\title{
Fasting and asthma: an opportunity for building patient-doctor partnership
}

Fasting has a very important place in most of the great world religions. The main fasting period for Christians is Lent, whereas in Judaism Yom Kippur and Tisha b'Av are the most widely practised days of fasting (although other 'minor' fasts may also be observed) [1]. Muslims fast during the month of Ramadan this being regarded as one of the 'Pillars of Faith'. Devout religious observance in Buddhism and Hinduism also demands fasting. The raison d'être common to these various religious traditions is that fasting helps individuals, through temporarily abstaining from the material pleasures of life, to develop spiritually. But why, if fasting is primarily a spiritual exercise, may the knowledge that your patient with asthma is fasting be important?

Asthma-a chronic inflammatory lung disease characterised by recurrent episodes of breathlessness, wheezing, coughing, chest tightness-is one of the most prevalent chronic diseases worldwide. It is responsible for hundreds of thousands of accident and emergency department visits and hospitalisations, and an estimated 1400 deaths, each year in the UK. The cornerstone of asthma management-of achieving control of the underlying disease process and minimising disruption of personal, professional and social lives-is use of bronchodilators and, for the majority of patient's, concordance with agreed anti-inflammatory regimens. The importance of this lies in the fact that attitudes to medication usage whilst fasting varies between and indeed within religious traditions and it is therefore important that appropriate enquiries are made so as to facilitate culturally competent and sensitive asthma care.

Various traditions and religions suggest to their members the form of fasting to adopt: eating only one meal, abstaining from meat, taking only 'bread and water', or not eating and drinking from sunrise to sunset. While Christianity, reformed Judaism and Hinduism does not regard taking medication (including inhalers) as breaking the fast, for Orthodox Jews and Muslims the exclusion of food extends (in general terms) to the taking of medication also. Orthodox Jewish patients on medication may therefore seek permission to fast from a Rabbi. In Islamic teachings, fasting is excused for those with iltnesses in whom medical opinion suggests that fasting may endanger health. Our experiences however "suggest that most Muslims will often wish to fast because of the spiritual importance of Ramadan. As many patients are unable to discuss this issue meaningfully with their clinicians, most will therefore stop taking their regular asthma medication during the month of Ramadan [2].

In view of the one moth duration of Ramadan and the knowledge that many fasting Muslims discontinue treatment whilst fasting, we focus in the reminder of this paper on considering the needs of Muslim patients. It may be helpful then if clinicians are aware that there are a range of opinions among Muslims on whether using inhaled medication contravenes the fast (see Box 1). When faced with the Muslim patient who is fasting it is therefore important to enquire about what types of drug treatment the patient considers acceptable. Through dialogue between health professionals and patients, it is usually possible to facilitate safe fasting for those who wish to observe this important religious rite. For those who wish to abstain completely also from inhalers, drawing on evidence-based guidelines, one may consider switching standard treatments to a regimen comprising of long-acting $\beta-2$ agonists and/or once or twice daily inhaled steroid regimens that can be taken before dawn and after sunset.

It is important that healthcare professionals develop a relationship with their Muslim patients 


\section{Box 1.}

Most Islamic scholars agree that the use of oral medication nullifies the fast [6]. With regards inhalers, injections, topical treatments, and suppositories many authorities would consider these forms of treatment to be acceptable whilst fasting [7-9]. Dr. Muzammil Siddiqi, former president of the Islamic Society of North America and member of the Fiqh Council of North America, says: "The use of an inhaler during fasting is permissible because the inhaler only provides some moisture; it does not involve the taking in of any liquid or food through the mouth. Even when we take a breath, we take in some moisture into our throats and that does not break our fast. Therefore, in any similar way, the use of an inhaler is permissible"' [10].

The late Saudi scholar Sheikh Abdul-'Azeez Ibn Baz, said in one of his religious edicts: "The use of inhaler is permissible in case of necessity, based on the (Qur'anic) verse:" '... and He has already made plain to you what He has forbidden to you-excepting what you are compelled to ...' Inhalers do not resemble food or drink; they are similar to taking non-nutritional injections" [10].

\section{Copyrlght}

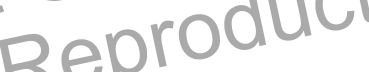

with asthma that is built on respect so that they will feel comfortable to come and consult them on these issues [3]; and to ensure that those who chose to abstain from using inhaled treatments whilst fasting do so as safely as possible. This seasonal lapse of compliance has been recognised as a cause of deterioration in asthma symptoms.

It is prudent that people with asthma wishing to fast are assessed and appropriately advised before the month of Ramadan and that their asthma control and suitability for fasting is determined. Asking whether they have fasted before and how this affected asthma may provide helpful insight in developing a suitable self-management plan which should include amongst other things clear criteria under which it is important that the fast be suspended and medical attention sought. Such shared decision-making is crucial in order to achieve culturally competent care and regular taking of medications that reduces both the frequency and severity of asthma symptoms $[4,5]$.

The period of fasting, be it Ramadan for Muslims or Lent for Christians, is a time when those who fast are invited not just to abstain from food but also to stop smoking. Therefore, these times represent an ideal opportunity to look for synergies and deliver smoking cessation advice. Such initiatives are well underway in Britain with successful partnerships between The Muslim Council of Britain, Department of Health and British Heart Foundation that have led to the development of a welcome annual 'Stop smoking for Ramadan' campaign.

In conclusion, religious practices can have a considerable effect on the experience and outcomes of illness. Discovering what patients believe about asthma (or any other illness) is not only intriguing for those of us who value the human dimension to the art of caring but can also be important in reconciling differences between what doctors want patients to do and what patients think they should do for treating their asthma [11]. It is an essential part of building patient-doctor partnership.

\section{Statement(s) of conflict of interest}

AS chairs the Research and Documentation Committee of The Mustim Council of Britain.

\section{References}

[1] Berner YN. Fasting, food composition, health and belief. Isr Med Assoc J 2001;3:667-8.

[2] Sheikh A, Gatrad R, editors. Caring for Muslim Patients. Abingdon: Radcliffe Medical Press; 2000.

[3] Car J, Freeman GK. Conceptualisation of patient-doctor partnership. Ljubljana: WONCA Europe 2003, Book of abstracts: 201.

[4] Yee L, Breaking Barriers: Towards Culturally Competent General Practice. Exeter: RCGP; 1997.

[5] Car J, Freeman GK, Griffiths C, Sheikh A, Rhodes T, Ashcroft RE, et al. Exploring patient-doctor partnership in white European and south Asian adults with asthma: qualitative interview study. Prim Care Resp J 2003;12:69.

[6] Sheikh A. Death and dying-a Muslim perspective. JR Soc Med 1998;91:138-40.

[7] Sheikh A. Medical implications of controlled fasting. JR Soc Med 1998;91(8):453.

[8] Masri GM. Introduction to Islam. Beirut: Dar Ibn Hazm; 1997. p. 65-8.

[9] Al-Munajjid SM. Seventy issues related to fasting. http:// www. islam-qa.com/ (accessed 1 December 2003).

[10] IslamOnline.net. Does using an asthma inhaler break the fast? http://www.islamonline.net/fatwa/english/ FatwaDisplay.asp?hFatwalD=20225 (accessed 1 December 2003).

[11] Connett GJ, Lee BW. Treating childhood asthma in Singapore: when West meets East. BMJ 1994;308:1282-4.

Josip Car

Centre for Primary Care and Social Medicine Imperial College London, London, UK 
Aziz Sheikh* Division of Community Health Sciences GP Section, University of Edinburgh, Edinburgh, UK
*Corresponding author. Tel.: +44-131-651-4151

fax: +44-131-650-9119

E-mail address: aziz.sheikh@ed.ac.uk (A. Sheikh)

Available online at www.sciencedirect.com

science@Direct.

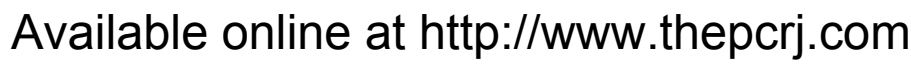

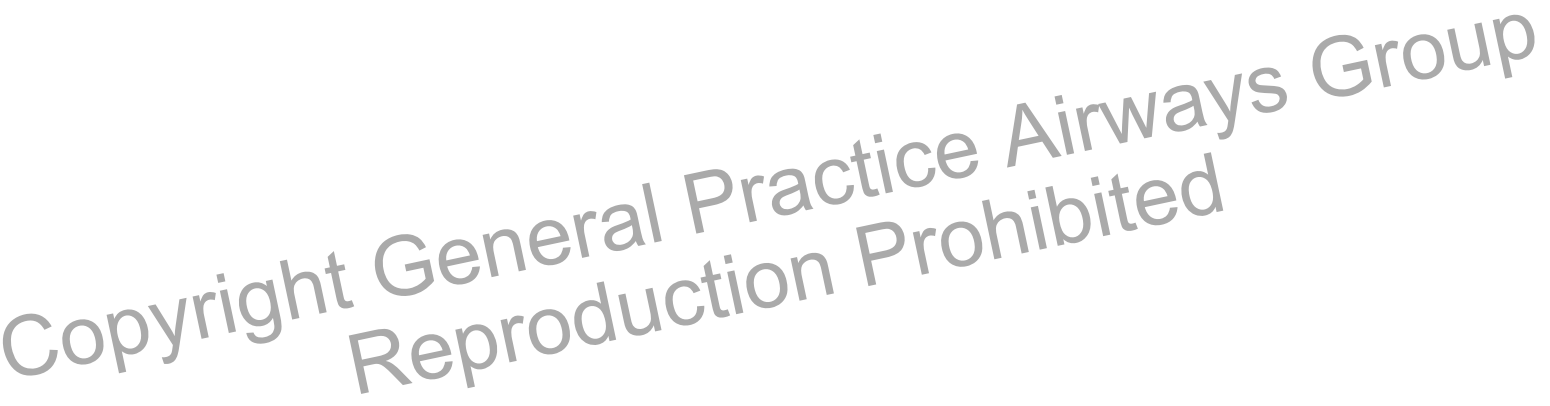

